\title{
DC-Link Current Control with Inverter Nonlinearity Compensation for Permanent Magnet Synchronous Motor Drives
}

\author{
Kan Wang ${ }^{(}$, Zhong $\mathrm{Wu} * \mathbb{1}$ and Zhongyi Chu \\ School of Instrumentation and Optoelectronic Engineering, Beihang University, Beijing 100191, China; \\ stjing01@buaa.edu.cn (K.W.); chuzy@buaa.edu.cn (Z.C.) \\ * Correspondence: wuzhong@buaa.edu.cn; Tel.: +86-10-8233-9703
}

Received: 22 December 2019; Accepted: 20 January 2020; Published: 22 January 2020

\begin{abstract}
For permanent magnet synchronous motors (PMSMs) supplied with a voltage source inverter, current control strategies are commonly implemented under the synchronously rotating reference frame. In order to simplify the system structure, three-phase currents can be measured with a single DC-link current sensor using the phase current reconstruction technique. However, it still needs to follow the conventional AC current control approach. In this paper, a DC-link current control method for PMSMs is proposed to further simplify the control system. The problem of phase current control was separated into the problems of amplitude control and phase control. Then, amplitude control was achieved using a closed-loop controller directly tracking the DC-link current; while phase control was achieved by AC-side pulse width modulation (PWM) following the phase angle of back electromotive force. The compensation for nonlinear distortion of the inverter was taken into account during the control process. Finally, the proposed method realized three-phase current control with a single current sensor and controller, and achieved the purpose of electromagnetic torque control. Experimental results demonstrate the effectiveness of the proposed method.
\end{abstract}

Keywords: permanent magnet synchronous motor (PMSM); phase current control; voltage source inverter (VSI); system simplification; DC-link current

\section{Introduction}

Owing to their advantages of high power density, high torque inertia ratio and wide speed range, permanent magnet synchronous motors (PMSMs) have been widely used in motion control fields such as aerospace, weaponry, industrial robots, and computer numerical control (CNC) machines [1-4]. Generally, PMSMs are powered by a three-phase voltage source inverter (VSI) [5,6]. According to rotor position and speed, VSI supplies terminal voltages to stator windings of PMSM through PWM to generate stator currents.

The electromagnetic torque of PMSM is generated by the interaction between rotor permanent magnet and alternating magnetic field formed by stator currents [7]. Thus, torque performance is generally affected by the accuracy of current control. At present, research on current control strategies has become a constant theme in the field of PMSM servo control.

In most PMSM applications, a two-phase current control strategy under the synchronously rotating reference frame ( $\mathrm{d}-\mathrm{q}$ reference frame) is commonly used [8-10]. Three-phase alternating stator currents are measured and projected onto d-axis and q-axis that parallel and perpendicular to rotor poles through coordinate transformations, and the purpose is to convert the problem of $\mathrm{AC}$ current control under a stationary reference frame into the problem of DC current control under a rotating reference frame. By tracking the converted d-q axis currents, respectively, d-q axis control voltages are generated 
and then inversely transformed to the terminal voltages of three-phase stator windings. Considering the fact that actual terminal voltages will be distorted due to nonlinear characteristics of VSI, such as dead time, turn-on/turn-off delay and forward voltage drop of power devices [11], nonlinearity compensation is usually introduced in control strategies to optimize phase current waveforms [12-14].

In order to simplify system structure and avoid disturbance due to mismatches of sensor characteristics, an interesting research topic has emerged in recent years that replaces traditional phase current measurement with reconstruction [15-20]. Since each switching state of VSI corresponds to a specific conduction relationship between DC-link and AC-link, three-phase currents can be sequentially measured by a single DC-link current sensor as switching state changes [15]. However, there are some reconstruction dead zones in the space vector plane, such that the duration of switching state is not sufficient for accurate current sampling [16]. Generally, these reconstruction dead zones need to be narrowed by PWM modification, such as measurement vector insertion [17] and switching-state phase shift [18]. In an earlier study [19], the authors proposed to reduce the effect of dead zones by adjusting the position of current sensor and sampling during zero voltage vectors. In another earlier study [20], a single current sensor was used to sample at multiple positions during both zero vectors and active vectors so that the phase currents were accurately reconstructed. Phase current reconstruction technique only requires a single DC-link current sensor, which simplifies the system structure in feedback channel. However, it still needs to follow the conventional AC current control approach based on the $\mathrm{d}-\mathrm{q}$ reference frame.

In this paper, a DC-link current control method for PMSMs is proposed in order to further simplify the system structure. The problem of phase current control was separated into the problems of amplitude control and phase control. Then, amplitude control was achieved on the DC side of VSI by directly using DC-link current as the control variable; while phase control was achieved on the AC side of VSI by PWM following the phase angle of back electromotive force (EMF). Nonlinear distortion of VSI was also compensated for during the control process. As a result, the proposed method can simply implement current control of PMSM without phase current reconstruction and coordinate transformations, and finally achieve electromagnetic torque control.

\section{System Model and Problem Formulation}

The diagram of an equivalent circuit for conventional VSI-PMSM system is shown in Figure 1. Generally, the DC side of VSI is supplied with a constant voltage, while the AC side generates three-phase terminal voltages through PWM to power the stator windings of PMSM.

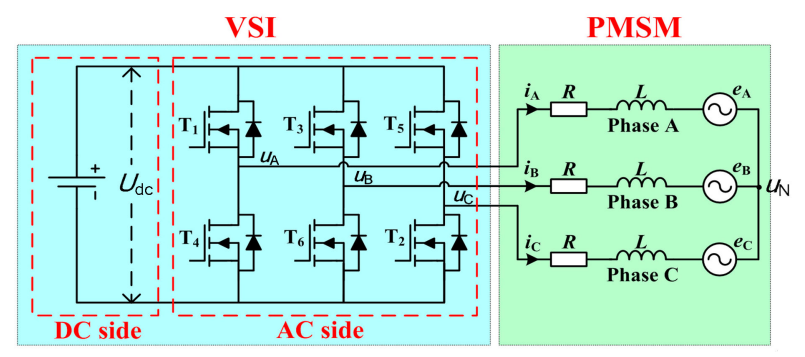

Figure 1. Diagram of equivalent circuit for a voltage source inverter (VSI)-permanent magnet synchronous motor (PMSM) system.

\subsection{PMSM Model}

For a surface-mounted PMSM supplied with VSI in Figure 1, the equation of terminal voltages can be written as [21].

$$
u_{\mathrm{s}}=R i_{\mathrm{s}}+L \frac{d i_{\mathrm{s}}}{d t}+e+u_{\mathrm{N}}
$$


where $u_{\mathrm{s}}=\left[\begin{array}{lll}u_{\mathrm{A}} & u_{\mathrm{B}} & u_{\mathrm{C}}\end{array}\right]^{\mathrm{T}}, i_{\mathrm{s}}=\left[\begin{array}{lll}i_{\mathrm{A}} & i_{\mathrm{B}} & i_{\mathrm{C}}\end{array}\right]^{\mathrm{T}}$, and $\boldsymbol{e}=\left[\begin{array}{lll}e_{\mathrm{A}} & e_{\mathrm{B}} & e_{\mathrm{C}}\end{array}\right]^{\mathrm{T}}$ represent terminal voltages, phase currents, and EMFs of stator windings, respectively; $R$ and $L$ are equivalent stator resistance and inductance, respectively; $\boldsymbol{u}_{\mathrm{N}}$ is neutral-point voltage of stator windings.

For convenience, PMSM is assumed to have ideal back EMFs with sinusoidal waveforms expressed as

$$
\boldsymbol{e}=p \psi_{\mathrm{m}} \omega_{\mathrm{m}} S\left(\theta_{\mathrm{e}}\right)
$$

where $\psi_{\mathrm{m}}$ and $p$ denote the amplitude of the rotor flux linkage and the number of pole pairs, respectively; $\omega_{\mathrm{m}}$ and $\theta_{\mathrm{e}}$ denote mechanical speed and electrical angle of the rotor, respectively; $S\left(\theta_{\mathrm{e}}\right)=\left[\sin \left(\theta_{\mathrm{e}}\right)\right.$, $\left.\sin \left(\theta_{\mathrm{e}}-2 \pi / 3\right), \sin \left(\theta_{\mathrm{e}}+2 \pi / 3\right)\right]^{\mathrm{T}}[21]$.

Typically, the phase currents through stator windings should have coincident phase angles with back EMFs in order to realize maximum torque per ampere (MTPA). Thus, the ideal phase currents should be

$$
i_{\mathrm{s}}=S\left(\theta_{\mathrm{e}}\right) I
$$

where I is the amplitude of the phase currents.

Without consideration of cogging effects and other non-ideal factors of PMSM, the electromagnetic torque can be written as

$$
T_{\mathrm{e}}=\frac{\boldsymbol{e}^{\mathrm{T}} \boldsymbol{i}_{\mathrm{s}}}{\omega_{\mathrm{m}}}=\frac{3}{2} p \psi_{\mathrm{m}} I
$$

where $T_{\mathrm{e}}$ represents the electromagnetic torque of PMSM [22].

\subsection{Nonlinear Distortion of VSI}

However, the torque performance of PMSM is usually degraded by the total harmonic distortion (THD) of three-phase terminal voltages. The main factors introducing harmonic distortion are some nonlinear characteristics of VSI, such as dead time, turn-on/turn-off delay and forward voltage drop of power devices. The distortion voltages caused by these nonlinearities can be expressed as

$$
\begin{gathered}
\boldsymbol{v}_{\mathrm{dt}}=\operatorname{sgn}\left(\boldsymbol{i}_{\mathrm{s}}\right) t_{\mathrm{dt}} f_{\mathrm{s}} U_{\mathrm{dc}} \\
v_{\mathrm{st}}=\operatorname{sgn}\left(\boldsymbol{i}_{\mathrm{s}}\right)\left(t_{\mathrm{on}}-t_{\mathrm{off}}\right) f_{\mathrm{s}} U_{\mathrm{dc}} \\
\boldsymbol{v}_{\text {on }}=R_{\mathrm{on}} i_{\mathrm{s}}+V_{\mathrm{th}} \operatorname{sgn}\left(\boldsymbol{i}_{\mathrm{s}}\right)
\end{gathered}
$$

where $v_{\mathrm{dt}}, v_{\mathrm{st}}$ and $v_{\text {on }}$ represent the distortion voltages caused by dead time, turn-on/turn-off delay and forward voltage drop, respectively; $t_{\mathrm{dt}}, t_{\mathrm{on}}$ and $t_{\text {off }}$ represent the dead time, turn-on and turn-off delay times, respectively; $f_{\mathrm{s}}$ and $U_{\mathrm{dc}}$ are the switching frequency and DC-link voltage of VSI, respectively; $R_{\text {on }}$ and $V_{\text {th }}$ represent the average on-state resistance and average threshold voltage of single switching device and its anti-parallel diode, respectively; $\operatorname{sgn}(\cdot)$ is a signum function [23-25].

If the on-resistance $R_{\text {on }}$ is considered as a part of stator resistance $R$, the total nonlinear voltage $v_{\text {err }}$ of VSI can be derived as

$$
v_{\mathrm{err}}=v_{\mathrm{dt}}+v_{\mathrm{st}}+\left(v_{\mathrm{on}}-R_{\mathrm{on}} i_{\mathrm{s}}\right)=A_{\mathrm{err}} \operatorname{sgn}\left(i_{\mathrm{s}}\right)
$$

where $A_{\mathrm{err}}=\left(t_{\mathrm{dt}}+t_{\mathrm{on}}-t_{\mathrm{off}}\right) f_{\mathrm{s}} U_{\mathrm{dc}}+V_{\mathrm{th}}[26]$.

In order to suppress non-ideal current harmonics and torque ripples, compensation for nonlinear distortion of VSI is necessary.

\subsection{Problem Formulation}

Generally, electromagnetic torque control of PMSM is implemented by controlling phase currents. In conventional drive systems, the d-q reference frame-based control strategy is commonly used, as shown in Figure 2. The three-phase AC currents $i_{\mathrm{s}}$ in stator windings are projected onto d-axis 
and q-axis through coordinate transformation to get the control variables $i_{\mathrm{d}}$ and $i_{\mathrm{q}}$. Since the $\mathrm{d}$-axis and q-axis are always kept parallel and perpendicular to rotor poles, respectively, the problem of the AC current control is converted into the problem of DC current control. $i_{\mathrm{d}}$ and $i_{\mathrm{q}}$ are tracked by two closed-loop current controllers, respectively. As a result, control voltages $u_{\mathrm{d}}$ and $u_{\mathrm{q}}$ are output and coupled into three-phase terminal voltages $\boldsymbol{u}_{\mathrm{s}}$ by inverse coordinate transformation.

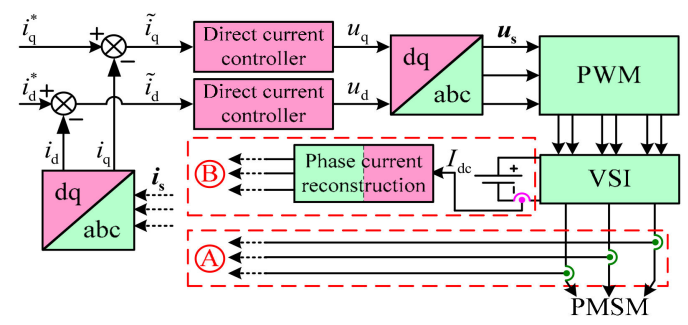

Figure 2. Diagram of conventional current control system of PMSM.

In order to simplify the system structure, there has been a new research interest in recent years that adopts phase current reconstruction instead of traditional direct measurement (that is, replaces A with B in Figure 2). Through this technique, three-phase currents can be reconstructed with a single DC-link current sensor according to the switching state of VSI. In this way, the number of current sensors required in the feedback channel can be reduced; while in the control channel, the conventional strategy based on the d-q reference frame is still used.

In fact, the transformation from sampled current $I_{\mathrm{dc}}$ to control variables $i_{\mathrm{d}}$ and $i_{\mathrm{q}}$ in a system based on phase current reconstruction is a process of DC-AC-DC, as shown in Figure 3. If the measured DC-link current $I_{\mathrm{dc}}$ can be directly used as the control variable of phase currents without reconstruction and coordinate transformation, system structure may be further simplified.

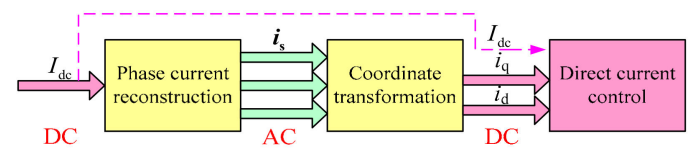

Figure 3. Transformation from sampled current to control variable.

Hence, a novel control strategy is proposed in this paper. It can be seen in Equation (4) that the electromagnetic torque of PMSM is linearly related to the amplitude of phase currents in-phase with back EMFs. Thus, we can directly divide the problem of phase current control into two parts, that is, phase control and amplitude control. Phase control can be implemented by following the phase angles of back EMFs; while the amplitude of phase currents can be directly controlled by DC-link current. In this way, we can get the required phase currents and finally achieve the purpose of electromagnetic torque control.

\section{Proposed Method}

In this section, a DC-link current control method of PMSM is proposed. Firstly, we discuss how to determine the relationship between the amplitude of phase currents and DC-link current, and then design a reference DC-link current. Secondly, we describe how amplitude control of phase currents is implemented on the DC side of VSI by tracking the designed reference DC-link current, and how phase control is implemented by AC-side PWM following the phase angle of back EMF. Finally, a discussion is provided for the proposed method. A detailed introduction is given as follows.

\subsection{Design of Reference DC-Link Current}

In order to control the amplitude $I$ of phase currents by DC-link current $I_{\mathrm{dc}}$, first we determine the relationship between $I_{\mathrm{dc}}$ and $I$. 
According to the law of energy conservation, the input and output power of VSI can be expressed as

$$
U_{\mathrm{dc}} I_{\mathrm{dc}}=\boldsymbol{u}_{\mathrm{s}}^{\mathrm{T}} \boldsymbol{i}_{\mathrm{s}}+\boldsymbol{v}_{\mathrm{err}}^{\mathrm{T}} \boldsymbol{i}_{\mathrm{s}}
$$

where $\boldsymbol{u}_{\mathrm{s}}^{\mathrm{T}} \boldsymbol{i}_{\mathrm{S}}$ represents the power consumption of PMSM, and $\boldsymbol{v}_{\mathrm{err}}^{\mathrm{T}} \boldsymbol{i}_{\mathrm{S}}$ represents the power loss due to nonlinear distortion of VSI.

Substituting Equations (1) and (8) into Equation (9) gives

$$
U_{\mathrm{dc}} I_{\mathrm{dc}}=R \boldsymbol{i}_{\mathrm{s}}^{T} \boldsymbol{i}_{\mathrm{s}}+L \frac{d \boldsymbol{i}_{\mathrm{s}}^{T}}{d t} \boldsymbol{i}_{\mathrm{s}}+\boldsymbol{e}^{\mathrm{T}} \boldsymbol{i}_{\mathrm{s}}+A_{\mathrm{err} \operatorname{sgn}}\left(\boldsymbol{i}_{\mathrm{s}}^{\mathrm{T}}\right) \boldsymbol{i}_{\mathrm{s}}
$$

According to Equations (2) and (3), it is easy to know $\boldsymbol{i}_{\mathrm{s}}^{\mathrm{T}} \boldsymbol{i}_{\mathrm{s}}=3 I^{2} / 2,\left(d \boldsymbol{i}_{\mathrm{s}}^{\mathrm{T}} / d t\right) \boldsymbol{i}_{\mathrm{s}}=0, \boldsymbol{e}^{\mathrm{T}} \boldsymbol{i}_{\mathrm{s}}=3 p \psi_{m} I / 2$, $\operatorname{sgn}\left(\boldsymbol{i}_{\mathrm{s}}^{\mathrm{T}}\right) \boldsymbol{i}_{\mathrm{s}}=\operatorname{If}\left(\theta_{\mathrm{e}}\right)$, and $f\left(\theta_{\mathrm{e}}\right)=\left|\sin \theta_{\mathrm{e}}\right|+\left|\sin \left(\theta_{\mathrm{e}}-\pi / 3\right)\right|+\left|\sin \left(\theta_{\mathrm{e}}+2 \pi / 3\right)\right|$. Thus, Equation (10) can be rewritten as

$$
U_{\mathrm{dc}} I_{\mathrm{dc}}=\left(\frac{3}{2} U+A_{\mathrm{err}} f\left(\theta_{\mathrm{e}}\right)\right) I
$$

where $U=R I+p \psi_{\mathrm{m}} \omega_{\mathrm{m}}$ can be approximated as the amplitude of terminal voltages $\boldsymbol{u}_{\mathrm{s}}$ in steady state.

According to the principle of PWM, there is a physical relationship between DC-link voltage and the amplitude of AC voltages as follows:

$$
U_{\mathrm{amp}}=\rho k_{\mathrm{u}} U_{\mathrm{dc}}
$$

where $U_{\mathrm{amp}}$ represents the amplitude of modulated AC voltages $u_{\mathrm{ac}}, \rho$ represents the modulation ratio of PWM, which is the amplitude ratio of modulation wave to triangle carrier and there is $0 \leq \rho \leq 1$; $k_{\mathrm{u}}$ represents the maximal utilization of DC-link voltage for a certain PWM mode. In SPWM mode, $k_{\mathrm{u}}=0.5$; while in SVPWM mode, $k_{\mathrm{u}}=0.577[27,28]$. In order to output the expected terminal voltages $\boldsymbol{u}_{\mathrm{s}}$, modulated AC voltages $\boldsymbol{u}_{\mathrm{ac}}$ should compensate for nonlinear distortion $\boldsymbol{v}_{\mathrm{err}}$. That is, $\boldsymbol{u}_{\mathrm{ac}}=\boldsymbol{u}_{\mathrm{s}}+\boldsymbol{v}_{\mathrm{err}}$, as shown in Figure 4. Thus, there is $U_{\mathrm{amp}}=U+A_{\mathrm{err}}$.

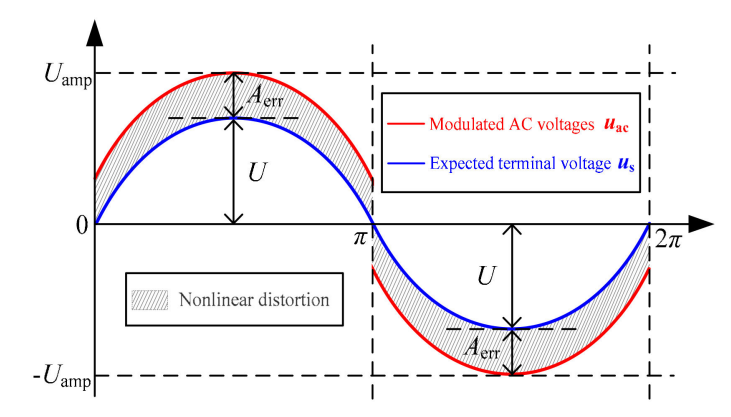

Figure 4. Diagram of inverter nonlinearity compensation.

Submitting Equation (12) into Equation (11) gives

$$
I_{\mathrm{dc}}=\frac{3}{2} \rho k_{\mathrm{u} I}\left[1+\left(\frac{2}{3} f\left(\theta_{\mathrm{e}}\right)-1\right) \frac{A_{\mathrm{err}}}{U_{\mathrm{amp}}}\right]
$$

Generally, $A_{\text {err }}$ is very small for most MOSFETs and Schottky diodes. Therefore, it can be considered that $\left(2 f\left(\theta_{\mathrm{e}}\right) / 3-1\right) A_{\mathrm{err}} / U_{\mathrm{amp}} \ll 1$, and then Equation (13) can be approximated as

$$
I_{\mathrm{dc}} \approx \frac{3}{2} \rho k_{\mathrm{u}} I
$$

Based on Equation (14), we can directly convert the measured $I_{\mathrm{dc}}$ to $I$ and design the amplitude controller of phase currents with conventional control variable $\rho$. In this way, the fundamental amplitude $U$ of terminal voltages is adjusted with $\rho$, but harmonic distortion $A_{\mathrm{err}}=\left(t_{\mathrm{dt}}+t_{\mathrm{on}}-\right.$ 
$\left.t_{\text {off }}\right) f_{\mathrm{s}} U_{\mathrm{dc}}+V_{\text {th }}$ is almost unchanged with a constant $U_{\mathrm{dc}}$. Obviously, the THD of $u_{\mathrm{ac}}$ will increase as $\rho$ is reduced. Therefore, the current control performance may deteriorate when the modulation ratio of PWM is low (such as low-speed and low-power situations).

Extensive studies have shown that increasing the utilization for DC-link voltage is beneficial to suppress switching losses and nonlinear distortions of VSI [29-31]. In order to avoid the deterioration of control performance caused by low modulation ratio, we locked the modulation ratio $\rho=1$ to achieve the maximal utilization of DC-link voltage when PMSM works in the low speed range. Hence, the reference DC-link current $I_{\mathrm{dc}}^{*}$ for an expected amplitude $I^{*}$ of phase currents can be designed from Equation (14) as

$$
I_{\mathrm{dc}}^{*}=\frac{3}{2} k_{\mathrm{u}} I^{*}
$$

\subsection{Implementation of Current Control}

Based on the reference DC-link current in Equation (15), the implementation method for phase current control was designed and the schematic diagram is shown in Figure 5. Since we decoupled the problem of phase current control into the problems of amplitude control and phase control, the control method was designed by two steps accordingly.

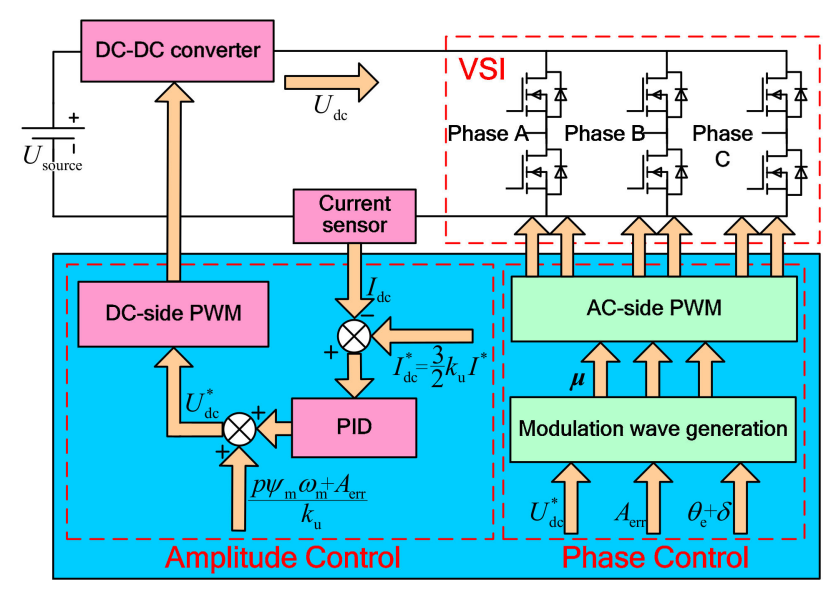

Figure 5. Schematic diagram of the proposed method.

Firstly, amplitude control of phase currents is achieved on the DC side of VSI through tracking the reference DC-link current. It can be seen in Equation (12) that the DC-link voltage $U_{\mathrm{dc}}$ should be adjustable to control $U_{\mathrm{amp}}$ since the modulation ratio is set to $\rho=1$. In order to achieve the expected amplitude $I^{*}$ of phase currents, the corresponding DC-link voltage in steady state should be given as

$$
\left.U_{\mathrm{dc}}\right|_{I=I^{*}}=\left.\frac{1}{k_{\mathrm{u}}} U_{\mathrm{amp}}\right|_{I=I^{*}}=\frac{1}{k_{\mathrm{u}}}\left(R I^{*}+p \psi_{\mathrm{m}} \omega_{\mathrm{m}}+A_{\mathrm{err}}\right)
$$

Hence, an open-loop controller can be designed to achieve $I^{*}$ by simply supplying the DC link with $U_{\mathrm{dc}} I_{I}=I^{*}$ if the model in Equation (16) is accurate enough. However, there are inevitable parameter uncertainties and unmodeled dynamics in actual systems, which may limit the accuracy of open-loop control. Therefore, it is necessary to design a closed-loop current controller.

Since $I^{*}$ can be converted to the reference $I_{\mathrm{dc}}^{*}$ by Equation (15), DC-link current $I_{\mathrm{dc}}$ is directly used as the feedback of closed-loop controller without phase current reconstruction and coordinate transformations. The controller $U_{\mathrm{dc}}^{*}$ is designed as

$$
U_{\mathrm{dc}}^{*}=\left(K_{\mathrm{P}} \tilde{I}_{\mathrm{dc}}+K_{\mathrm{I}} \int_{0}^{t} \tilde{I}_{\mathrm{dc}} d \tau\right)+\frac{1}{k_{\mathrm{u}}}\left(p \psi_{\mathrm{m}} \omega_{\mathrm{m}}+A_{\mathrm{err}}\right)
$$


where $\tilde{I}_{\mathrm{dc}}=I_{\mathrm{dc}}^{*}-I_{\mathrm{dc}} ; K_{\mathrm{P}}$ and $K_{\mathrm{I}}$ are proportional and integral gains of the controller, respectively. The controller in Equation (17) consists of two parts, that is, a proportional integral (PI) controller and a feedforward compensator.

Based on the controller in Equation (17), the closed-loop control system for the DC-link current is shown in Figure 6. In Figure 6a, the DC-DC converter is utilized to produce DC-link voltage $U_{\mathrm{dc}}$ according to the controller output $U_{\mathrm{dc}}^{*}$ by using DC-side PWM; the transfer function $1 /\left(L_{\mathrm{dc}} S+R_{\mathrm{dc}}\right)$ represents the equivalent model of stator windings on DC side; $R_{\mathrm{dc}}$ and $L_{\mathrm{dc}}$ represent equivalent resistance and inductance on DC side, respectively. Furthermore, Figure 6a can be simplified to Figure $6 \mathrm{~b}$ if both dynamic and steady-state errors of DC-DC converter are denoted by the lumped disturbance $d$ and $U_{\mathrm{dc}}=U_{\mathrm{dc}}^{*}+d$.

By tuning controller gains $K_{\mathrm{P}}$ and $K_{\mathrm{I}}, \mathrm{DC}$-link current $I_{\mathrm{dc}}$ can track its reference $I_{\mathrm{dc}}^{*}$ accurately. Simultaneously, the amplitude of terminal voltages is adjusted corresponding to DC-link voltage $U_{\mathrm{dc}}$. In this way, amplitude control of phase currents can be achieved, as shown in Figure 6.

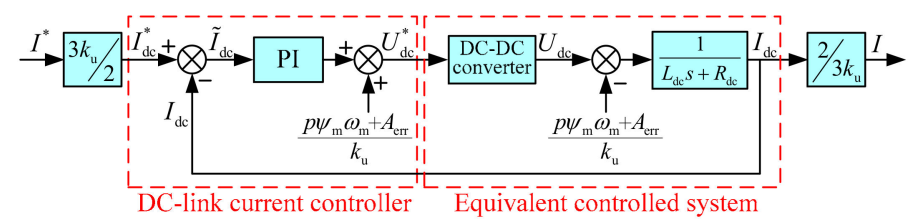

(a)

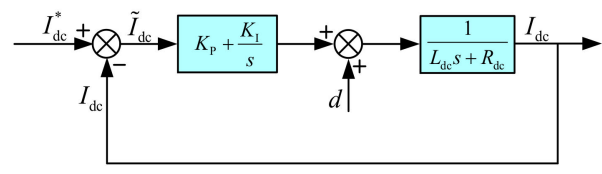

(b)

Figure 6. Implementation of DC-link current control. (a) schematic diagram of control system; (b) simplified diagram.

Secondly, phase control of phase currents is achieved on AC side of VSI through following the phase angle of back EMF. In order to ensure that each phase current is always in-phase with the corresponding back EMF, the modulation wave of AC-side PWM should be determined to generate the expected terminal voltage.

As shown in Figure 4, the modulated AC voltage with inverter nonlinearity compensation is $u_{\mathrm{ac}}=$ $u_{\mathrm{s}}+\boldsymbol{v}_{\text {err }}$. Thus, the expected AC voltages in steady state can be given by

$$
\boldsymbol{u}_{\mathrm{ac}}^{*}=\boldsymbol{u}_{\mathrm{s}}^{*}+\boldsymbol{v}_{\mathrm{err}}=\left(U_{\mathrm{amp}}^{*}-A_{\mathrm{err}}\right) \boldsymbol{S}\left(\theta_{\mathrm{e}}+\delta\right)+A_{\mathrm{err}} \operatorname{sgn}\left[\boldsymbol{S}\left(\theta_{\mathrm{e}}+\delta\right)\right]
$$

where $u_{\mathrm{ac}}^{*}$ and $u_{\mathrm{s}}^{*}$ represent the expected modulated voltages and terminal voltages, respectively; $U_{\mathrm{amp}}^{*}$ is the amplitude of $\boldsymbol{u}_{\mathrm{ac}}^{*} ; \delta$ is a phase advance angle that compensates for system delay and the impedance angle; $S\left(\theta_{\mathrm{e}}+\delta\right)=\left[\sin \left(\theta_{\mathrm{e}}+\delta\right), \sin \left(\theta_{\mathrm{e}}+\delta-2 \pi / 3\right), \sin \left(\theta_{\mathrm{e}}+\delta+2 \pi / 3\right)\right]^{\mathrm{T}}$. Generally, the phase advance angle $\delta$ can be obtained by offline measurement or online estimation [32,33].

Since $U_{\mathrm{amp}}^{*}$ is controlled by $U_{\mathrm{dc}}^{*}$ on DC side and the modulation ratio of AC-side PWM is set to $\rho=1$, the modulation wave should be the normalized waveform function of $\boldsymbol{u}_{\mathrm{ac}}^{*}$, that is

$$
\boldsymbol{\mu}=\frac{\boldsymbol{u}_{\mathrm{ac}}^{*}}{U_{\mathrm{amp}}^{*}}=\left(1-\frac{A_{\mathrm{err}}}{k_{\mathrm{u}} U_{\mathrm{dc}}^{*}}\right) \boldsymbol{S}\left(\theta_{\mathrm{e}}+\delta\right)+\frac{A_{\mathrm{err}}}{k_{\mathrm{u}} U_{\mathrm{dc}}^{*}} \operatorname{sgn}\left[\boldsymbol{S}\left(\theta_{\mathrm{e}}+\delta\right)\right]
$$

It can be seen in Equation (19) that the output $U_{\mathrm{dc}}^{*}$ of DC-side controller also needs to be used for modulation wave generation on AC side in order to realize accurate nonlinearity compensation. In this way, the expected terminal voltage can be generated by AC-side PWM with the modulation wave $\mu$ in Equation (19). 
Finally, phase current control of PMSM is implemented by controlling the amplitude and phases separately. Since the electromagnetic torque is linearly related to the amplitude of phase currents in MTPA mode according to Equation (4), the proposed DC-link current control method can achieve electromagnetic torque control.

\subsection{Discussion}

Considering that the torque performance of PMSM is susceptible to nonlinear distortion of VSI in low modulation area of PWM, a DC-DC converter is usually used to provide DC-link voltage adapting to the operating point of PMSM, especially for motor drives with a wide speed range [31,34]. Based on similar topologies, we lock the modulation ratio $\rho=1$ and achieve amplitude control with the maximum utilization for DC-link voltage to improve the control accuracy in the proposed method. On the other hand, amplitude control of the proposed method can also be achieved with conventional control variable $\rho$ if the DC-DC converter is not used.

Compared with conventional current control methods, the one proposed here has certain advantages in simplicity and practicality since the implementation only needs one current sensor and controller without complex coordinate transformations.

\section{Experimental Results}

In order to verify the proposed DC-link current control method, an experimental platform was built in this study, which consisted of a test PMSM, a load motor and a drive and control board, as shown in Figure 7. The angular position/speed sensor is a resolver mounted on the PMSM. The main parameters of PMSM are listed in Table 1.

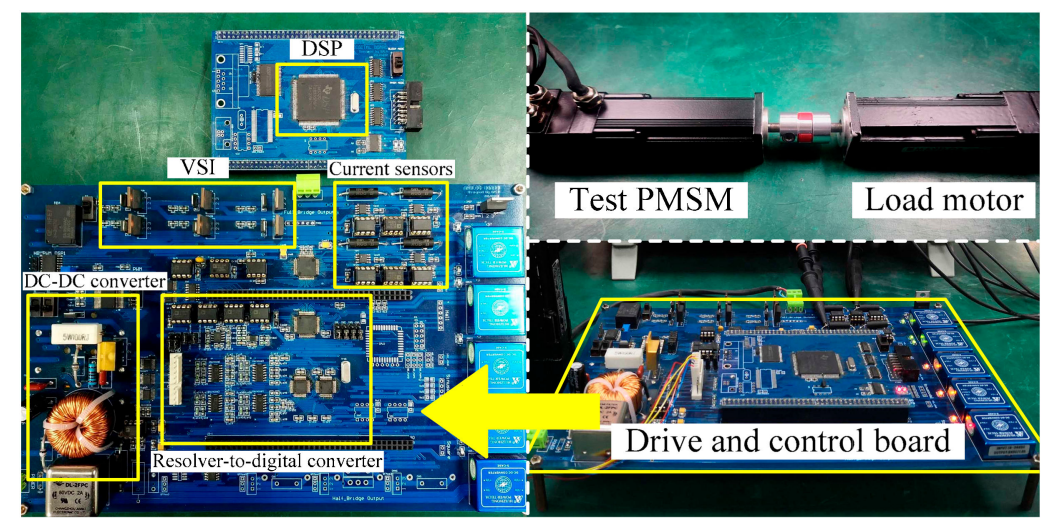

Figure 7. Experimental platform.

Table 1. Main parameters of test PMSM.

\begin{tabular}{llll}
\hline Pole Pairs & 2 & Rated Voltage & $3000 \mathrm{r} / \mathrm{min}$ \\
Torque coefficient & $0.09 \mathrm{Nm} / \mathrm{A}$ & Phase resistance & $1.2 \Omega$ \\
Sliding friction & $0.06 \mathrm{Nm}$ & Phase inductance & $2 \mathrm{mH}$ \\
\hline
\end{tabular}

The drive and control board uses DSP-TMS320F28335 as the microprocessor and integrates the DC-DC converter, VSI circuit, current detection circuit and resolver-to-digital conversion circuit, and so on. The current sensor is a current shunt monitor INA286 from the Texas Instruments Company. The switching device of VSI is a MOSFET IRFR3910 from the Infineon Company, and the anti-parallel diode is a FYP2006DN from the Fairchild Company. The switching frequency was set to $15-\mathrm{kHz}$. Considering the propagation delay of the driver IC, the dead time was set to $1 \mu$ s.

To directly reflect current control accuracy, only the current loop was closed in the experiment. The expected amplitude of phase currents was given as $I^{*}=0.6 \mathrm{~A}$ and $I^{*}=2$ A respectively to verify the performance of the proposed method under a steady state. According to Equation (15), the 
reference DC-link current under SPWM mode should be set as $I_{\mathrm{dc}}^{*}=0.45 \mathrm{~A}$ and $I_{\mathrm{dc}}^{*}=1.5 \mathrm{~A}$, respectively. Then, a reference current with step change was given to verify the dynamic performance of the method proposed.

\subsection{Current Control With $\mathrm{I}_{d c}^{*}=0.45 \mathrm{~A}$}

First, the expected amplitude of phase currents is set to $I^{*}=0.6 \mathrm{~A}$. Thus, the reference DC-link current of the proposed method should be given to $I_{\mathrm{dc}}^{*}=0.45 \mathrm{~A}$ according to Equation (15). The classic $i_{\mathrm{d}}=0$ control method based on three-phase currents feedback is adopted to compare with the proposed method under the same conditions.

In the experiment, the drive and control board was powered by a DC voltage source $U_{\text {source }}=$ $45 \mathrm{~V}$, and the DC-link voltage of the proposed method was adjusted by a DC-DC converter around $4.5 \mathrm{~V}$. In order to ensure the rationality of the comparison, the DC-link voltage of $i_{\mathrm{d}}=0$ control was reduced to $U_{\mathrm{dc}}=5 \mathrm{~V}$ through DC-DC converter to achieve similar utilization. The current control results of the two methods are shown in Figures 8 and 9, respectively.

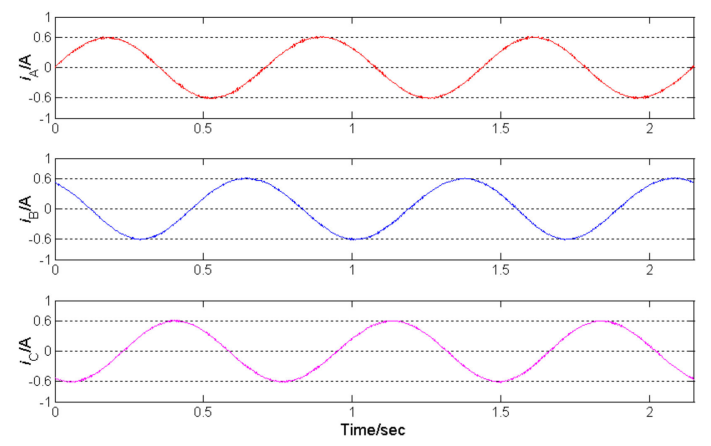

Figure 8. Current control results of $i_{\mathrm{d}}=0$ control.

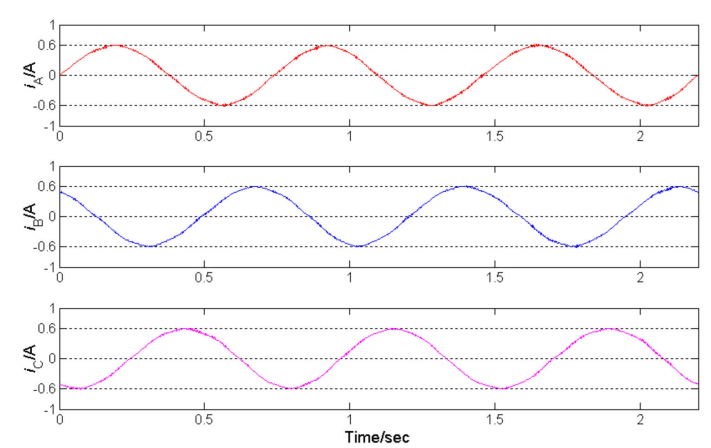

(a)

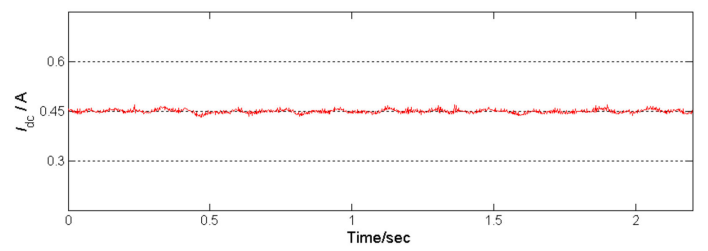

(b)

Figure 9. Current control results of proposed method. (a) Phase currents; (b) DC-link current.

In Figures 8 and 9a, it can be seen that the phase current results of the proposed method and $i_{\mathrm{d}}=$ 0 control both have amplitudes close to $0.6 \mathrm{~A}$. In order to compare the accuracy of controlled phase currents more clearly, we removed the fundamental component of each waveform in Figures 8 and $9 \mathrm{a}$ by fast Fourier transform (FFT), and the extracted harmonic components are shown in Figures 10 and 11 , respectively.

By comparing Figures 10 and 11, it can be seen that the harmonic content in the three-phase currents controlled by the proposed method is higher. However, the maximum amplitude of harmonic currents in Figure 11 is only about $0.05 \mathrm{~A}$, which is much smaller than the fundamental amplitude $0.6 \mathrm{~A}$.

Furthermore, we can evaluate the torque performance of PMSM based on current control results. According to (4), the ideal electromagnetic torque generated by three-phase sinusoidal currents with an amplitude of $0.6 \mathrm{~A}$ should be $T_{\mathrm{e}}^{*}=1.5 \times 0.09 \times 0.6=0.081 \mathrm{Nm}$; and the actual electromagnetic 
torque can be approximately calculated by $T_{\mathrm{e}}=\boldsymbol{e}^{\mathrm{T}} \boldsymbol{i}_{\mathrm{s}} / \omega_{\mathrm{m}}$. Therefore, we measured the actual back EMF waveforms of test PMSM with unit speed (that is, $e / \omega_{\mathrm{m}}$ ) in advance, and the result within one mechanical period is shown in Figure 12.

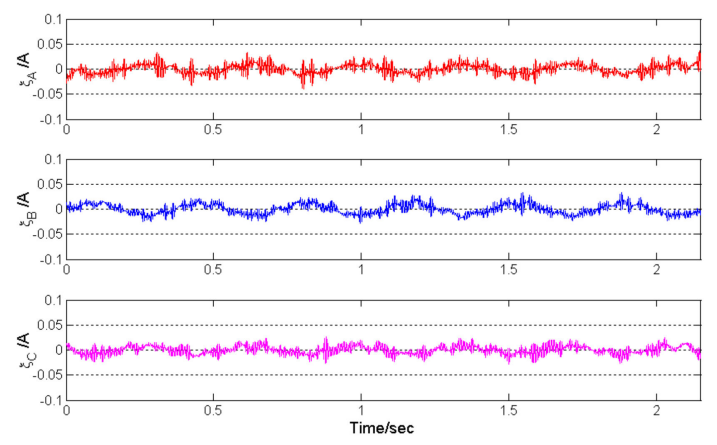

Figure 10. Harmonic currents of $i_{\mathrm{d}}=0$ control.
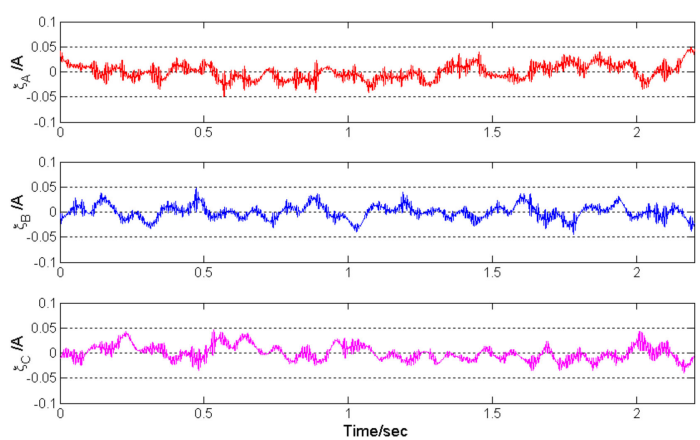

Figure 11. Harmonic currents of proposed method.

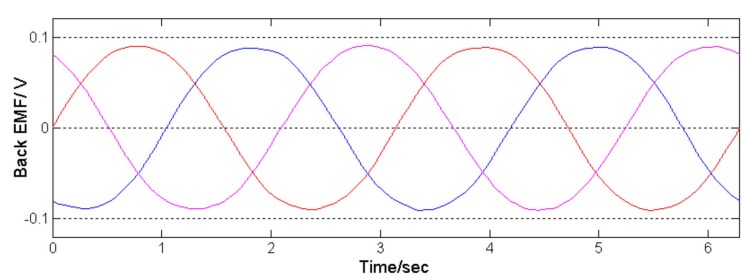

Figure 12. Back electromotive force (EMF) waveforms of test PMSM with unit speed.

Then, according to the results of three-phase currents in Figures 8 and $9 \mathrm{a}$, the actual electromagnetic torque achieved by the proposed method and $i_{\mathrm{d}}=0$ control can be evaluated, respectively, and the results are shown in Figures 13 and 14. It can be seen that the amplitudes of torque ripples in Figures 13 and 14 are similar. The peak-to-peak value, average value and standard deviation of the two evaluated torques are listed in Table 2 . The comparison between the proposed method and $i_{\mathrm{d}}=0$ control shows that each statistical value of the two evaluated torques is very similar. Therefore, the experimental results demonstrate that the proposed method can achieve similar torque control performance to $i_{\mathrm{d}}=0$ control under the same conditions.

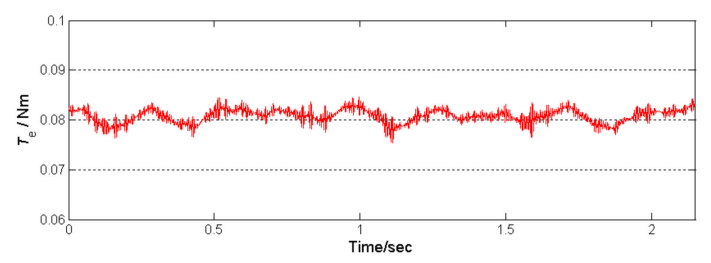

Figure 13. Electromagnetic torque of $i_{\mathrm{d}}=0$ control. 


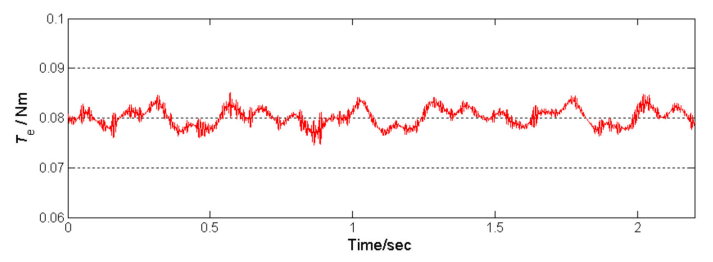

Figure 14. Electromagnetic torque of proposed method.

Table 2. Statistics of evaluated torque.

\begin{tabular}{ccc}
\hline Statistical Value $(\mathbf{N m})$ & $\boldsymbol{i}_{\mathbf{d}}=\mathbf{0}$ Control & Proposed Method \\
\hline$P-P$ value & 0.009646 & 0.010592 \\
Average value & 0.080794 & 0.080149 \\
Standard deviation & 0.001528 & 0.001854 \\
\hline
\end{tabular}

\subsection{Current Control With $I_{d c}^{*}=1.5 \mathrm{~A}$}

In order to further verify the control performance of the proposed method under different conditions, we increased the load of test PMSM and set $I^{*}=2 \mathrm{~A}$. Thus, the reference DC-link current of the proposed method should be given as $I_{\mathrm{dc}}^{*}=1.5 \mathrm{~A}$ according to (15), and the electromagnetic torque achieved should be $T_{\mathrm{e}}^{*}=1.5 \times 0.09 \times 2=0.27 \mathrm{Nm}$.

Similar to the previous experiment, we reduced $U_{\mathrm{dc}}$ to $9 \mathrm{~V}$ through DC-DC converter in the comparative experiment of $i_{\mathrm{d}}=0$ control to ensure the similar utilization since $U_{\mathrm{dc}}$ of the proposed method was adjusted around $8.5 \mathrm{~V}$. The current control results of the two methods are shown in Figures 15 and 16, respectively.
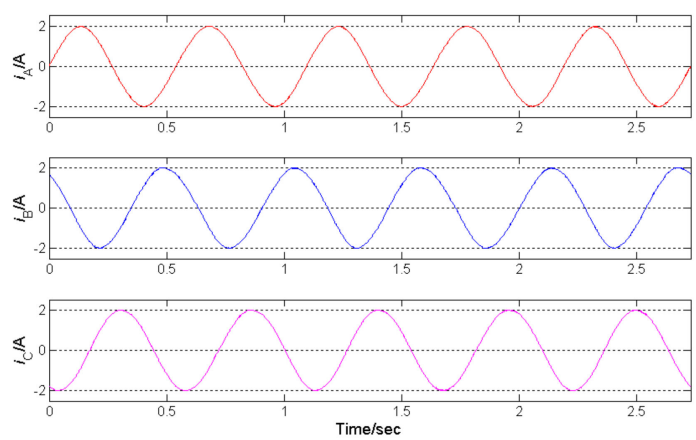

Figure 15. Current control results of $i_{\mathrm{d}}=0$ control.
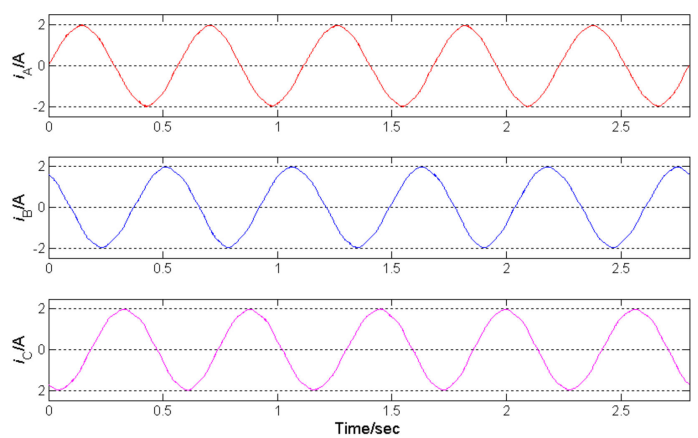

(a)

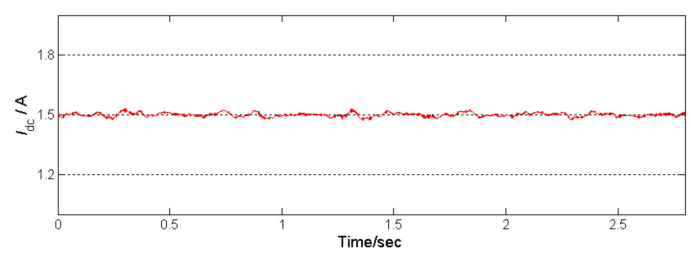

(b)

Figure 16. Current control results of proposed method. (a) Phase currents; (b) DC-link current.

It can be seen that both of the amplitudes of the three-phase currents in Figures 15 and 16a were about $2 \mathrm{~A}$. After removing the fundamental waves by FFT, harmonic components of the controlled phase currents in Figures 15 and 16a were extracted, as shown in Figures 17 and 18, respectively. 
Although the harmonic content in phase currents controlled by the proposed method was higher than that of $i_{\mathrm{d}}=0$ control, the maximum amplitude of harmonic currents is only about $0.1 \mathrm{~A}$ that far less than the fundamental amplitude. Therefore, the influence of these harmonics on electromagnetic torque is very limited.

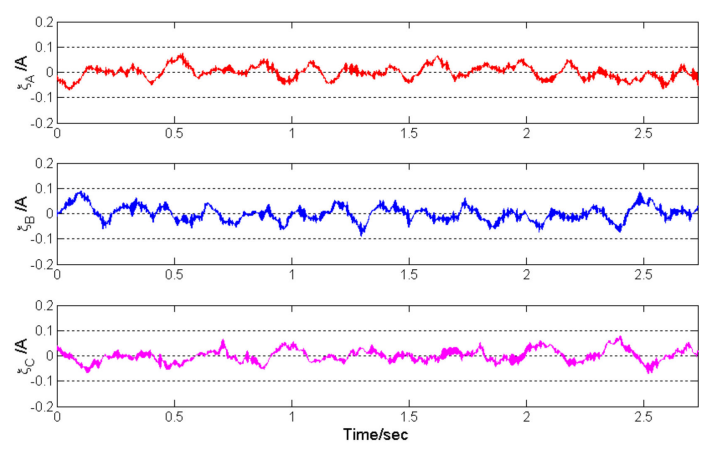

Figure 17. Harmonic currents of $i_{\mathrm{d}}=0$ control.

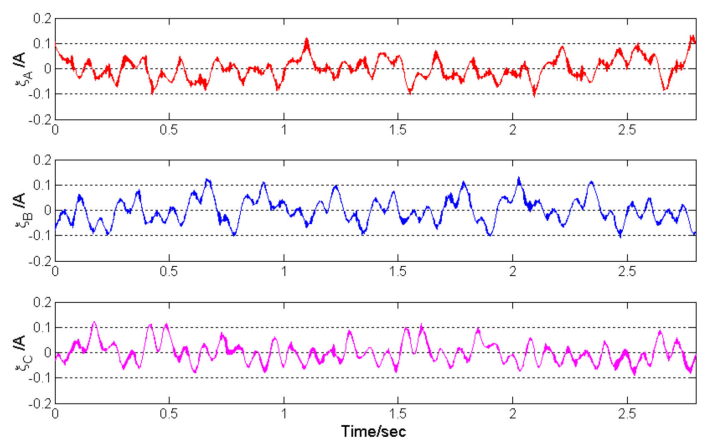

Figure 18. Harmonic currents of proposed method.

Based on the results of controlled phase currents in Figures 15 and 16a, the electromagnetic torque achieved by the proposed method and $i_{\mathrm{d}}=0$ control was evaluated by $T_{\mathrm{e}}=\boldsymbol{e}^{\mathrm{T}} \boldsymbol{i}_{\mathrm{s}} / \omega_{\mathrm{m}}$, respectively. The waveforms of the evaluated torque are shown in Figures 19 and 20. It can be seen that the amplitudes of torque ripples in the two waveforms were similar. Table 3 provides the statistics of the evaluated torque in Figures 19 and 20. The deviation of each statistical value between the proposed method and $i_{\mathrm{d}}=0$ control is within the order of magnitude of $10^{-3} \mathrm{Nm}$. Therefore, it can also be demonstrated under current conditions that the torque performance achieved by the proposed method and $i_{\mathrm{d}}=0$ control is almost equivalent.

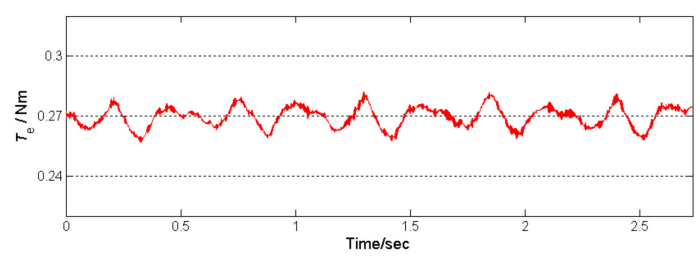

Figure 19. Electromagnetic torque of $i_{\mathrm{d}}=0$ control.

Table 3. Statistics of evaluated torque.

\begin{tabular}{ccc}
\hline Statistical Value $(\mathbf{N m})$ & $\boldsymbol{i}_{\mathbf{d}}=\mathbf{0}$ Control & Proposed Method \\
\hline$P-P$ value & 0.025168 & 0.028928 \\
Average value & 0.269608 & 0.267609 \\
Standard deviation & 0.005123 & 0.005910 \\
\hline
\end{tabular}




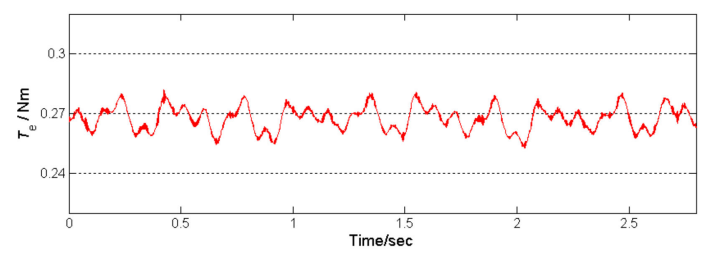

Figure 20. Electromagnetic torque of proposed method.

\subsection{Current Control With Step Change of $I_{d c}^{*}$}

In order to verify the dynamic performance of the proposed method, the reference DC-link current was given as a step change from $I_{\mathrm{dc}}^{*}=0.64 \mathrm{~A}$ to $1 \mathrm{~A}$. Ideally, the electromagnetic torque of test PMSM should step from $0.115 \mathrm{Nm}$ to $0.18 \mathrm{Nm}$ according to Equations (4) and (15).

If the proposed method and $i_{\mathrm{d}}=0$ control are given the same closed-loop gain and bandwidth by adjusting controller parameters, the current control results are shown in Figures 21 and 22, respectively.
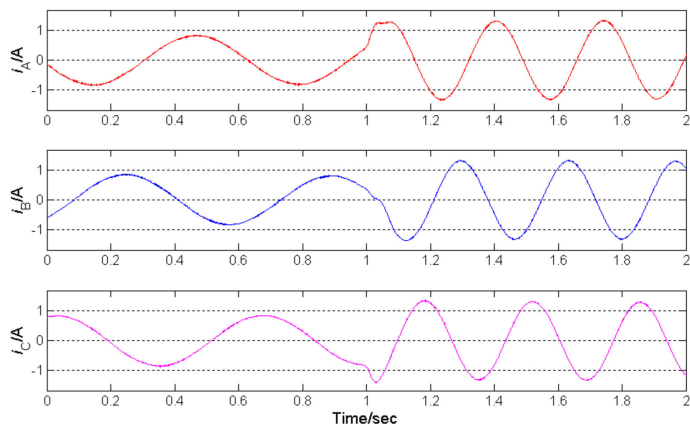

Figure 21. Current control results of $i_{\mathrm{d}}=0$ control.
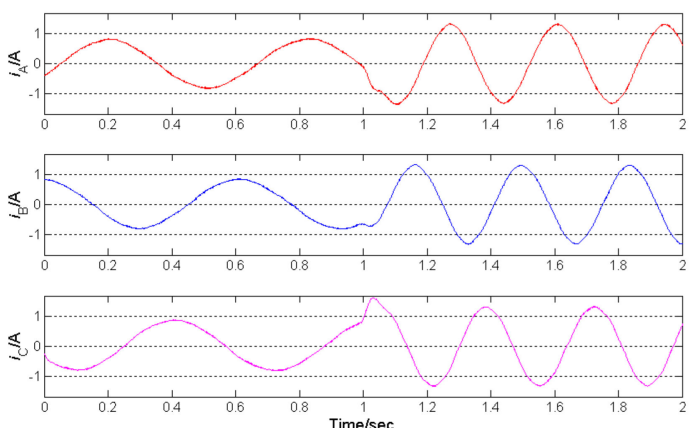

(a)

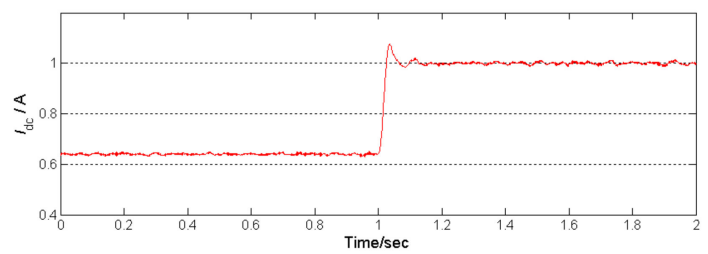

(b)

Figure 22. Current control results of proposed method. (a) Phase currents; (b) DC-link current.

Then, actual electromagnetic torque achieved by the two methods can be estimated from the results of three-phase currents in Figures 21 and 22, respectively, as shown in Figures 23 and 24. It can be seen that the overshoots of electromagnetic torque in Figures 23 and 24 are almost equal and the settling times are similar. The experimental results indicate that the step response of the proposed method and $i_{\mathrm{d}}=0$ control is similar under the same closed-loop control gain and bandwidth.

In the experiment described by this paper, the proposed DC-link current control method of PMSM was verified under steady state and dynamic conditions. The classic $i_{\mathrm{d}}=0$ control method with three-phase currents feedback was used for comparative experiment. Experimental results show that the proposed method can realize high-accuracy phase current control by directly controlling the DC-link current of VSI, and is almost equivalent to $i_{\mathrm{d}}=0$ control in terms of torque control performance. Therefore, the proposed method can provide simple implementation for phase current control of PMSM, since it only needs one current sensor and controller without complex coordinate transformations. 


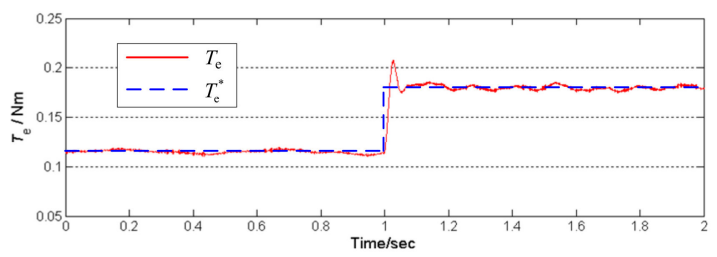

Figure 23. Electromagnetic torque of $i_{\mathrm{d}}=0$ control.

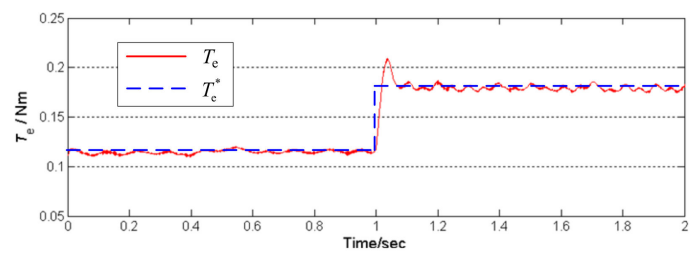

Figure 24. Electromagnetic torque of proposed method.

\section{Conclusions}

In this paper, a simple current control method of PMSM is proposed. The problem of three-phase current control was solved by controlling the amplitude and phases separately. Based on energy conservation between the DC and AC sides of VSI, amplitude of phase currents was controlled by a closed-loop controller that directly tracks the DC-link current. On the other hand, current phases were controlled by AC-side PWM with modulation waves following the phase angles of back EMFs. Nonlinear distortion of VSI was compensated during the control process. As a result, phase current control of PMSM can be implemented by a single current sensor and controller without complex coordinate transformations. Experimental results show that the proposed method can achieve similar torque control performance as $i_{\mathrm{d}}=0$ control with three-phase currents feedback.

Author Contributions: Conceptualization, Z.W.; methodology, K.W.; validation, K.W. and Z.C.; writing- original draft preparation, K.W. and Z.W. All authors have read and agreed to the published version of the manuscript.

Funding: This work was partially supported by The National Natural Science Foundation of China (U1913206).

Conflicts of Interest: The authors declare no conflict of interest.

\section{References}

1. Dong, S.; Zhang, Q.; Ma, H.; Wang, R. Design for the interior permanent magnet synchronous motor drive system based on the z-source inverter. Energies 2019, 12, 3350. [CrossRef]

2. You, Y.-M. Optimal design of PMSM based on automated finite element analysis and metamodeling. Energies 2019, 12, 4673. [CrossRef]

3. Ye, M.; Shi, T.; Wang, H.; Li, X.; Xia, C. Sensorless-MTPA control of permanent magnet synchronous motor based on an adaptive sliding mode observer. Energies 2019, 12, 3773. [CrossRef]

4. Lim, D.-K.; Yi, K.-P.; Jung, S.-Y.; Jung, H.-K.; Ro, J.-S. Optimal design of an interior permanent magnet synchronous motor by using a new surrogate-assisted multi-objective optimization. IEEE Trans. Magn. 2015, 51, 8207504. [CrossRef]

5. $\quad \mathrm{Mu}, \mathrm{X}$.; Chen, G.; Wang, X.; Zhao, J.; Wu, W.; Blaabjerg, F. Multi-frequency single loop passivity-based control for LC-filtered stand-alone voltage source inverter. Energies 2019, 12, 4548. [CrossRef]

6. Xia, C.; Wang, S.; Wang, Z.; Shi, T. Direct torque control for VSI-PMSMs using four-dimensional switching-table. IEEE Trans. Power Electron. 2016, 31, 5774-5785. [CrossRef]

7. Xu, J.X.; Panda, S.K.; Pan, Y.J.; Lee, T.H.; Lam, B.H. A modular control scheme for PMSM speed control with pulsating torque minimization. IEEE Trans. Ind. Electron. 2004, 51, 526-536. [CrossRef]

8. Yang, M.; Lang, X.; Long, J.; Xu, D. Flux immunity robust predictive current control with incremental model and extended state observer for PMSM drive. IEEE Trans. Power Electron. 2017, 32, 9267-9279. [CrossRef]

9. You, Z.C.; Huang, C.H.; Yang, S.M. Online current loop tuning for permanent magnet synchronous servo motor drives with deadbeat current control. Energies 2019, 12, 3555. [CrossRef] 
10. Zhang, X.; Hou, B.; Mei, Y. Deadbeat predictive current control of permanent magnet synchronous motors with stator current and disturbance observer. IEEE Trans. Power Electron. 2017, 32, 3818-3834. [CrossRef]

11. Pellegrino, G.; Guglielmi, P.; Armando, E.; Bojoi, R.I. Self-commissioning algorithm for inverter nonlinearity compensation in sensorless induction motor drives. IEEE Trans. Ind. Appl. 2010, 46, 1416-1424. [CrossRef]

12. Liu, K.; Zhu, Z.Q. Online estimation of the rotor flux linkage and voltage-source inverter nonlinearity in permanent magnet synchronous machine drives. IEEE Trans. Power Electron. 2014, 29, 418-427. [CrossRef]

13. Ludek, B.; Lukas, O. Online adaptive compensation scheme for inverter nonlinearity in PMSM drive. In Proceedings of the 7th International Congress on Ultra Modern Telecommunications and Control Systems and Workshops (ICUMT), Brno, Czech Republic, 6-8 October 2015; pp. 166-171.

14. Choi, C.; Cho, K.; Seok, J. Inverter nonlinearity compensation in the presence of current measurement errors and switching device parameter uncertainties. IEEE Trans. Power Electron. 2007, 22, 576-583. [CrossRef]

15. Carpaneto, M.; Fazio, P.; Marchesoni, M.; Parodi, G. Dynamic performance evaluation of sensorless permanent-magnet synchronous motor drives with reduced current sensors. IEEE Trans. Ind. Electron. 2012, 59, 4579-4589. [CrossRef]

16. Kim, H.; Jahns, T.M. Phase current reconstruction for AC motor drives using a DC link single current sensor and measurement voltage vectors. IEEE Trans. Power Electron. 2006, 21, 1413-1419. [CrossRef]

17. Lu, J.; Hu, Y.; Zhang, X.; Wang, Z.; Liu, J.; Gan, C. High-frequency voltage injection sensorless control technique for IPMSMs fed by a three-phase four-switch inverter with a single current sensor. IEEE/ASME Trans. Mechatron. 2018, 23, 758-768. [CrossRef]

18. Li, X.; Dusmez, S.; Akin, B.; Rajashekara, K. A new SVPWM for the phase current reconstruction of three-phase three-level T-type converters. IEEE Trans. Power Electron. 2016, 31, 2627-2637. [CrossRef]

19. Yan, H.; Xu, Y.; Zou, J. A phase current reconstruction approach for three-phase permanent-magnet synchronous motor drive. Energies 2019, 9, 853. [CrossRef]

20. Tang, Q.; Shen, A.; Li, W.; Luo, P.; Chen, M.; He, X. Multiple-positions-coupled sampling method for PMSM three-phase current reconstruction with a single current sensor. IEEE Trans. Power Electron. 2020, 35, 699-708. [CrossRef]

21. Krishnan, R. Permanent Magnet Synchronous and Brushless DC Motor Drives; CRC Press: Boca Raton, FL, USA, 2009.

22. Zhong, L.; Rahman, M.F.; Hu, W.Y.; Lim, K.W. A direct torque controller for permanent magnet synchronous motor drives. IEEE Trans. Energy Convers. 1999, 14, 637-642. [CrossRef]

23. Urasaki, N.; Senjyu, T.; Kinjo, T.; Funabashi, T.; Sekine, H. Dead-time compensation strategy for permanent magnet synchronous motor drive taking zero-current clamp and parasitic capacitance effects into account. IEE Proc. Electr. Power Appl. 2005, 152, 845-853. [CrossRef]

24. Raute, R.; Caruana, C.; Staines, C.S.; Cilia, J.; Sumner, M.; Asher, G.M. Analysis and compensation of inverter nonlinearity effect on a sensorless PMSM drive at very low and zero speed operation. IEEE Trans. Ind. Electron. 2010, 57, 4065-4074. [CrossRef]

25. Guerrero, J.M.; Leetmaa, M.; Briz, F.; Zamarron, A.; Lorenz, R.D. Inverter nonlinearity effects in high-frequency signal-injection-based sensorless control methods. IEEE Trans. Ind. Appl. 2005, 41, 618-626. [CrossRef]

26. Salt, D.E.; Drury, D.; Holliday, D.; Griffo, A.; Sangha, P.; Dinu, A. Compensation of inverter nonlinear distortion effects for signal-injection-based sensorless control. IEEE Trans. Ind. Appl. 2011, 47, 2084-2092. [CrossRef]

27. Lee, J.; Sun, Y. A new SPWM inverter with minimum filter requirement. Int. J. Electron. 1988, 64, 815-826. [CrossRef]

28. Kang, D.; Lee, Y.; Suh, B.; Choi, C.; Hyun, D. An improved carrier-based SVPWM method using leg voltage redundancies in generalized cascaded multilevel inverter topology. IEEE Trans. Power Electron. 2003, 18, 180-187. [CrossRef]

29. Fang, J.; Zhou, X.; Liu, G. Instantaneous torque control of small inductance brushless dc motor. IEEE Trans. Power Electron. 2012, 27, 4952-4964. [CrossRef]

30. Chen, W.; Liu, Y.; Li, X.; Shi, T.; Xia, C. A novel method of reducing commutation torque ripple for brushless DC motor based on cuk converter. IEEE Trans. Power Electron. 2017, 32, 5497-5508. [CrossRef]

31. Howlader, A.M.; Urasaki, N.; Senjyu, T.; Yona, A. Wide-speed-range optimal PAM control for permanent magnet synchronous motor. In Proceedings of the International Conference on Electrical Machines and Systems, Tokyo, Japan, 15-18 November 2009; pp. 98-102. 
32. Al-nabi, E.; Wu, B.; Zargari, N.R.; Sood, V. Input power factor compensation for high-power CSC fed PMSM drive using d-axis stator current control. IEEE Trans. Ind. Electron. 2012, 59, 752-761. [CrossRef]

33. Ahmed, A.; Sozer, Y.; Hamdan, M. Maximum torque per ampere control for buried magnet PMSM based on DC-link power measurement. IEEE Trans. Power Electron. 2017, 32, 1299-1311. [CrossRef]

34. Ou Yang, H.Y.; Lorenz, R.D. Torque ripple minimization in six-step PMSM drives via variable and fast DC bus dynamics. IEEE Trans. Ind. Appl. 2019, 55, 3791-3802. [CrossRef]

(C) 2020 by the authors. Licensee MDPI, Basel, Switzerland. This article is an open access article distributed under the terms and conditions of the Creative Commons Attribution (CC BY) license (http://creativecommons.org/licenses/by/4.0/). 